\title{
CREDIT CONSTRAINTS, CONSUMER LEASING AND THE AUTOMOBILE REPLACEMENT DECISION*
}

\author{
Kathleen W. Johnson \\ Board of Governors of the \\ Federal Reserve System \\ Mail Stop 93 \\ Washington, DC 20551 \\ (202) 452-3266 \\ kjohnson@frb.gov
}

\footnotetext{
* The views expressed are mine and do not necessarily reflect those of the Board of Governors or its staff. This paper is a revised version of my dissertation. I thank Roger Betancourt for several years of encouragement and support. I also thank Lawrence Ausubel, Igmar Prucha, Judith Hellerstein, Steve Oliner and Wayne Passmore for helpful suggestions. I have also benefited from the comments of seminar participants at the University of Maryland, the Department of Justice, Charles River Associates, the Southern Economic Association Meetings, as well as the Board of Governors of the Federal Reserve System. Any remaining errors are mine.
} 


\section{Introduction}

Since the early 1990's, more and more consumers have acquired a new car by leasing it rather than purchasing it. In 1992, consumers leased approximately 14 percent of their new car acquisitions. By 1996, they were leasing approximately 34 percent of their new car acquisitions. ${ }^{1}$

Despite the growing popularity of leasing, few researchers have studied the consumer's decision to lease an automobile. These researchers have taken two approaches to the leasing issue. Researchers such as Patrick (1984), Scerbinski (1988), Nunnally and Plath (1989) and Miller (1995) show how consumers can make this decision using a cash flow analysis. Miller (1995) improves upon these cash-flow analyses by considering the value of the option to purchase the vehicle at the end of the lease.

Others have modeled the consumer's decision to lease using incomplete information models. Using an adverse selection model, Hendel and Lizzeri (1998) demonstrate that consumers who place a high value on automobile quality choose a leasing contract because they are not likely to keep the automobile when it is used. By incorporating moral hazard into another adverse selection model, Guha and Waldman (1997) find that lessees are consumers with a high cost of maintaining their automobiles. They predict that high income consumers are more likely to lease because a higher cost of time leads to higher maintenance costs.

In this paper, I present a simple theoretical model of the effect of leasing contracts on the household's decision to enter the automobile market. I use the observation that lease contracts are shorter loans with better collateral protection in order to incorporate credit constraints into the model. This model generates several intuitively appealing results. I test two of these results, as well as the assumption that credit constraints matter in the leasing decision. I find that lessees appear more credit constrained and acquire more expensive automobiles than households that purchase do. In other ways, they resemble new car purchasers.

Section II below discusses some of the features of leasing contracts that may justify the use of a model of credit constraints. Section III presents the theoretical model and its conclusions. Section IV presents the empirical model, provides evidence that credit constraints do matter and tests some of the theoretical model's conclusions. Section V concludes the paper.

\footnotetext{
${ }^{1}$ CNW Marketing Research
} 


\section{Automobile Lease Contracts}

Automobile lease contracts provide households with the option to acquire an automobile by financing its user cost rather than its entire purchase price. These contracts specify the current and future value of the automobile, as well as the terms under which the household finances the difference between these two values.

Because households are financing the user cost over a period that is generally shorter than the automobile's useful life, the amount financed is less than the amount financed in a traditional loan contract. In addition, this amount is financed over a shorter period of time than a traditional loan contract. For example, in early 1999 the average length of a lease contract was a little over three years, while the average length of an automobile loan was approximately four and a half years. $^{2}$

Finally, lease contracts include several provisions that protect the loan collateral. For example, many contracts limit the number of miles that can be driven per year, thereby limiting the automobile's depreciation. These contracts generally limit the number of miles to anywhere between 10,000 and 15,000 miles.

Because a lease contract involves a smaller loan over a shorter period of time, and includes provisions which protect the loan's collateral, lenders may be more willing to offer a consumer a lease than extend a larger, lengthier, traditional loan.

If lenders are more willing to extend a lease than a loan for the same vehicle, household behavior will be affected. A household that cannot qualify for a loan large enough to purchase a particular automobile may be able to lease it. Therefore, households who have been turned down for credit would be more likely to lease an automobile. In addition, these households can lease a nicer automobile than the one they could purchase, therefore inducing them to acquire an automobile when they otherwise would not have.

III. Theoretical model of replacement with credit constraints

In this model, the household decides whether to keep its current automobile (k), to sell its automobile and purchase another $(\mathrm{P})$ or to sell its automobile and lease another $\{\mathrm{L}\}$. If the

\footnotetext{
${ }_{2}$ CNWW Marketing Research and Federal Reserve Board G.19 Statistical Release.
} 
household chooses to sell its automobile, the household must pay a transaction cost t to transact in the automobile market. Formally, it chooses an action $a \in(k, P, L)$ to solve equation 1 below.

(1) $\max _{a}\left(V_{k}, V_{P}, V_{L}\right)$

$\mathrm{V}_{\mathrm{a}}$ is the maximum utility that the household can attain, given that the household has chosen action $a \in(k, P, L)$. Therefore, $\mathrm{V}_{\mathrm{k}}$ is the utility that the household receives if it keeps its car, $V_{P}$ is the utility that the household receives if it sells its car and purchases another and $V_{L}$ is the utility that the household receives if it sells its car and leases another. These are the indirect utilities that result from the two-period maximization problem that I describe below.

In this two-period maximization problem, given its choice of action a, the household chooses the amount of income to spend on a non-durable good and on automobile services. It chooses consumption of the non-durable good $c \in[w, \infty)$, where $\mathrm{w}$ is a subsistence level of consumption and it pays a price of one dollar per unit of the non-durable good.

Households also choose their level of automobile services $s \in[0,1]$. All households have a common preference ordering over this interval, in which they prefer higher values of s to lower values. ${ }^{3}$ If a household chooses automobile services s today, then its level of automobile services tomorrow is $s \gamma$, where $\gamma \in(0,1) .^{4}$ The household pays $\mathrm{p}(\mathrm{s})$ for automobile services s, where ${ }^{5}$

$$
p(0)=0, \quad p(1)<\infty, \quad p^{\prime}(s)>0, \quad p^{\prime \prime}(s)>0, \quad \varepsilon=p^{\prime}(s) s / p(s)
$$

Given its choice of action a, the household chooses the amount of income to spend on the non-durable good and on automobile services. Formally, it chooses $c=\left(c_{1}, c_{2}\right)$ and $s=\left(s_{1}, s_{2}\right)$ to solve equation 3, where $U\left(c_{t}, s_{t}\right)$ is per period utility from the consumption of $c_{t}$ and $s_{\mathrm{t}}$ and the discount factor between the two periods is $\beta \in(0,1)$.

\footnotetext{
3 Each level of automobile services s, can be thought of as a distinct class of automobile. It should be noted that the common preference ordering is between automobile classes, not within classes. This assumption does not order the preferences between a Saturn and a Geo Prizm, but it does assume that a Mercedes C class (luxury class) is preferred to a Geo Prizm (compact class).

4 This specification of depreciation implies that a used car of a higher class renders the same services as a new car of a lower class.

5 The price function must be convex so that the service per dollar falls as the service rises. If instead, service per dollar were to rise with services and the consumer has enough income to purchase any variant of the good, then the consumer will always purchase $s=1$. Hence this assumption on the price function rules out the comer solution (Tirole 1988). Since the price function is convex in $\mathrm{s}, \mathrm{p}^{\mathrm{s}}(\mathrm{s}) \mathrm{s}>\mathrm{p}(\mathrm{s})$, and $\varepsilon>1$.
} 


$$
\max _{c, s} U\left(c_{1}, s_{1}\right)+\beta U\left(c_{2}, s_{2}\right)
$$

I make two additional simplifying assumptions. The first assumption is that per period utility is linear in non-durable consumption and automobile services, where the marginal rate of substitution between these two goods is subject to the following restrictions: ${ }^{6}$

$$
M R S_{c, s}=a_{2} / a_{1}=\theta, \quad \theta \in\left(0, \theta_{H}\right), \quad \theta_{H}<\infty
$$

The second assumption is that at the beginning of the second period, the household sells any automobile that it owns and consumes the proceeds as non-durables. This assumption reduces the number of choice variables from four to two by assuming that the consumption of automobile services tomorrow is zero and by linking the choice of automobile services and nondurables today to non-durable consumption tomorrow. ${ }^{7}$

These two simplifying assumptions reduce the maximization problem to equation 5, where $\mathrm{c}$ and $\mathrm{s}$ are scalars chosen in the first period and $E A(c, s)$ is the expected value of future assets measured in non-durables.

$$
\max _{c, s} a_{1} c+a_{2} s+\beta a_{1} E A(c, s)
$$

In order to purchase non-durable goods and automobile services, the household is endowed with income in the current period, $y_{c}>w$, uncertain future income $y_{f}>0$, and an initial level of automobile services $S \geq 0$. Assuming that $\mathrm{R}$ is the gross rate of return between periods, the household maximizes the utility given in equation 5 subject to the lifetime budget constraint in equation 6 if it has chosen to keep its automobile and maximizes utility subject to the lifetime budget constraint in equation 7 if it has chosen to purchase or lease another automobile.

$$
\begin{aligned}
& E y_{f}-R\left[c-y_{c}\right]+p(\gamma S)=0 \\
& E y_{f}-R\left[p(s)+t+c-y_{c}-p(S)\right]+\gamma^{\varepsilon} p(s)=0
\end{aligned}
$$

\footnotetext{
6 The marginal rate of substitution between non-durable consumption and automobile services can also be thought of as the household's willingness to pay for automobile services. Willingness to pay rises with $\mathbf{a}_{2}$ and falls with $\mathbf{a}_{1}$.

7 This assumption also makes the consumer's lifetime budget constraint the same whether she leases or purchases. Assuming that consumers who lease a car now will purchase the car in the future does not change the main results of this section. The results depend on borrowing constrained consumers choosing a different automobile under a leasing contract. The alternative assumption leaves the borrowing constraint unchanged. Nunnally and Plath (1989) assumes that the leased auto is purchased at the end of the lease. Patrick (1984) and Scerbinski (1988) assume that the purchased auto is sold at the end of the period.
} 
The assumptions that households must transact in the automobile market in order to change their level of automobile services and that they must pay a transaction cost to do so are responsible for these two different budget constraints. These assumptions are sufficient to generate a difference in utility between the option to keep the endowed automobile and the option to replace it. Since purchasing and leasing are both means by which a household replaces an automobile, these assumptions are not sufficient to generate a difference between the option to purchase an automobile and the option to lease it. An additional assumption is necessary.

This additional assumption is motivated by the observation that a household that cannot qualify for a loan large enough to purchase a particular automobile may be able to lease it. I introduce a borrowing constraint by assuming that the household can borrow against expected future income, but the debt payment incurred must be smaller than a fraction of current income $d \in(0,1)$. This assumption creates a distinct borrowing constraint for each of the three options. It does this because under each of the three options, the household is financing different amounts. The borrowing constraints for keeping and purchasing and leasing are given by equations 8,9 and 10 respectively, where I assume that the lease price of the automobile is equal to its user cost.

$$
\begin{aligned}
& R\left[c-y_{c}\right] \leq d y_{c} \\
& R\left[p(s)+t+c-y_{c}-p(S)\right] \leq d y_{c} \\
& R\left[p(s)\left(1-\frac{\gamma^{\varepsilon}}{R}\right)+t+c-y_{c}-p(S)\right] \leq d y_{c}
\end{aligned}
$$

The indirect utility $\left(\mathrm{V}_{\mathrm{a}}\right)$ of each action, $a \in(k, P, L)$, is the maximum utility obtainable (equation 5), given the relevant budget constraint for each action (equation 6 or 7), the relevant borrowing constraint for each action (equation 8, 9 or 10) and the constraint that non-durable good consumption is no less than a subsistence level, $c \geq w$. The indirect utility of each action has a functional form that depends on which constraints are binding.

The relative magnitudes of some of the parameters determine which constraints bind and therefore determine the indirect utility's functional form. The relative magnitudes of the gross rate of return, $\mathrm{R}$, and the discount factor, $\beta$, are one determinant of the indirect utility's functional form. These relative magnitudes determine whether the subsistence constraint is binding. A 
discount factor that is less than the inverse of the gross rate of return $(\beta<1 / R)$ results in a nonbinding subsistence constraint. This relatively low discount factor induces the household to borrow and to consume more than the subsistence level. A discount factor that is greater than the inverse of the gross rate of return $(\beta>1 / R)$ results in a binding subsistence constraint. This high relative discount factor induces the household to consume as little of the non-durable good today as possible. To reduce the number of functional forms to deal with and to focus on the borrowing constraint, I assume that all households have a relatively high discount factor (low rate of time discount) so that the subsistence constraint always binds. ${ }^{8}$

This assumption reduces the number of functional forms in the solution for $\mathrm{V}_{\mathrm{k}}$ from two to one. Previously, either the subsistence constraint or the borrowing constraint could bind. ${ }^{9}$ This assumption restricts the solution to the one with a binding subsistence constraint. This assumption also reduces the number of functional forms in the solution for $\mathrm{V}_{\mathrm{P}}$ and $\mathrm{V}_{\mathrm{L}}$. It only reduces the number of functional forms from three to two, because there is nothing to keep the borrowing and subsistence constraints from simultaneously binding. The indirect utility $\left(\mathrm{V}_{\mathrm{a}}\right)$ of each action, $a \in(k, P, L)$ are in equations 11-15, where $V_{a}^{B}$ denotes the indirect utility of action a when the borrowing constraint is binding and $V_{a}^{N}$ denotes the indirect utility of action a when the borrowing constraint is not binding, and where $h()=p^{-1}()$ and $g()=p^{,-1}()$.

$$
\begin{aligned}
& V_{k}^{N}=a_{1} w+a_{2} S+\beta a_{1}\left\{E y_{f}-R\left(w-y_{c}\right)+\gamma^{\varepsilon} p(S)\right\} \\
& V_{P}^{B}=a_{1} w+a_{2} h\left[\left(1+\frac{d}{R}\right) y_{c}+p(S)-t-w\right]+\beta a_{1}\left\{E y_{f}-d y_{c}+\gamma^{\varepsilon} p\left(h\left[\left(1+\frac{d}{R}\right) y_{c}+p(S)-t-w\right]\right)\right\} \\
& V_{P}^{N}=a_{1} w+a_{2} g\left(\frac{\theta}{\beta\left(R-\gamma^{\varepsilon}\right)}\right)+\beta a_{1}\left\{E y_{f}+\left(\gamma^{\varepsilon}-R\right) p\left(g\left(\frac{\theta}{\beta\left(R-\gamma^{\varepsilon}\right)}\right)\right)+R\left[y_{c}+p(S)-t-w\right]\right\}
\end{aligned}
$$

8 See Johnson (1999) for a discussion of the case in which the subsistence constraint does not bind.

Both constraints cannot bind because of the assumption that consumers receive enough current income to purchase more than the subsistence level of non-durable goods. If both constraints were to bind, the household has consumed its current income, plus the maximum amount it can borrow, but it only consumes a subsistence level of non-durables. This solution violates the assumption above. The case in which neither bind is not optimal. This is due to the linearity of utility in the non-durable good. If $\beta R>1$, then it is optimal to reduce current non-durable good consumption as much as possible, in which case the subsistence constraint binds. If $\beta R<1$, the consumer wishes to consume as much current non-durable as possible, in which case the borrowing constraint binds. The budget constraint always binds because utility is strictly increasing in each good. 


$$
\begin{aligned}
& V_{L}^{B}=a_{1} w+a_{2} h\left\{\frac{R}{R-\gamma^{\varepsilon}}\left[\left(1+\frac{d}{R}\right) y_{c}+p(S)-t-w\right]\right\}+\beta a_{1}\left\{E y_{f}-d y_{c}\right\} \\
& V_{L}^{N}=a_{1} w+a_{2} g\left(\frac{\theta}{\beta\left(R-\gamma^{\varepsilon}\right)}\right)+\beta a_{1}\left\{E y_{f}+\left(\gamma^{\varepsilon}-R\right) p\left(g\left(\frac{\theta}{\beta\left(R-\gamma^{\varepsilon}\right)}\right)\right)+R\left[y_{c}+p(S)-t-w\right]\right\}
\end{aligned}
$$

These solutions have at least two notable characteristics. First, current consumption of the non-durable good is always w. The household consumes this level of consumption because of the assumption that its discount factor is greater than the inverse of the gross return $(\beta>1 / R)$. Second, $V_{P}^{N}=V_{L}^{N}$. Without a binding borrowing constraint, the household is indifferent between purchasing and leasing.

For $\mathrm{a}=\mathrm{P}$ and $\mathrm{a}=\mathrm{L}$, the household's income and willingness to pay ( $\mathrm{y}_{\mathrm{c}}$ and $\theta$ ) determine whether it is borrowing constrained when it chooses action a. Therefore, these parameters determine whether the household receives utility $V_{a}=V_{a}^{N}$ or $V_{a}=V_{a}^{B}$ from action a. Using the borrowing constraints given in equations 9 and 10, Figure 1 graphs the values of $\mathrm{y}_{\mathrm{c}}$ and $\theta$ at which these constraints just bind. A household with income below line "a" is borrowing constrained when they choose action "a", and therefore $V_{a}=V_{a}^{B}$

Figure 1: Borrowing Constrained v. Not Constrained

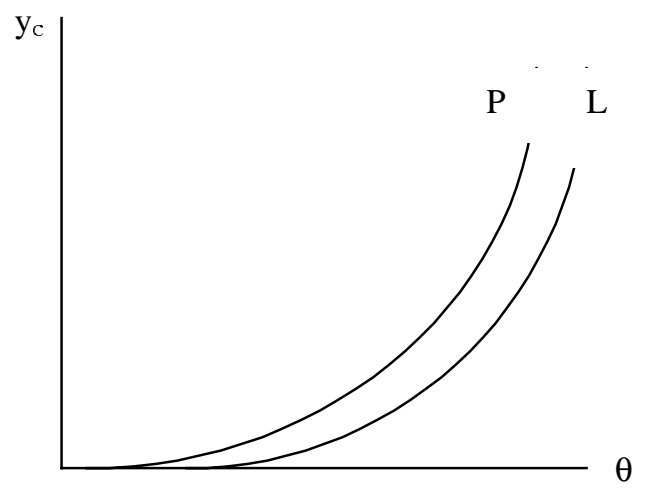

These lines rise with the household's willingness to pay because a household with a high willingness to pay desires a more expensive automobile and is more easily borrowing constrained. The line for $\mathrm{a}=\mathrm{P}$ is above the line for $\mathrm{a}=\mathrm{L}$ because of the assumption that leasing relaxes the borrowing constraint for a given choice of automobile.

The previous result implies that for a given choice of automobile, the household cannot be constrained from leasing the automobile, while at the same time be unconstrained from purchasing 
it. This reduces the number of possible comparisons of equations 11-15. The remaining possible maximization problems that the household can face are summarized in equation 16.

$$
\begin{aligned}
& \max _{a}\left(V_{k}^{N}, V_{P}^{N}, V_{L}^{N}\right) \\
& \max _{a}\left(V_{k}^{N}, V_{P}^{B}, V_{L}^{N}\right) \\
& \max _{a}\left(V_{k}^{N}, V_{P}^{B}, V_{L}^{B}\right)
\end{aligned}
$$

\section{A. Implications of theoretical model}

The comparisons of these utilities give a number of intuitively appealing results. The first two results are related to the general question of automobile replacement. The second two results pertain specifically to leasing and the next section of this paper will test these implications in an empirical model.

Proposition 1: A borrowing constrained household will not replace its automobile if its current and borrowed income is less than the transaction cost of replacement, plus the subsistence level of consumption. (See Appendix for proof).

Proposition 2: As the transaction cost decreases a household is more likely to replace its automobile. (See Appendix for proof)

This second result is similar to Bar-Ilan and Blinder (1992). The household's decision to keep their automobile or to replace it by choosing $\mathrm{a}=\mathrm{P}$ or $\mathrm{L}$ is straightforward. If the difference between the level of automobile services that household would choose if they replaced their automobile and the level they currently receive is large enough to justify paying the transaction cost, then the household replaces. As the transaction cost tends to zero, the household will always replace, regardless of its preference for automobiles. ${ }^{10}$

\footnotetext{
10 If the household's income is such that it is not borrowing constrained, then the household's choice of $\mathrm{s}$ is independent of its level of income and therefore, its replacement decision is independent of its income. If the household's income is such that it is borrowing constrained, the optimal automobile is an increasing function of income. Therefore, the replacement decision is also a function of the household's income level. This outcome is analogous to models of differentiated products. In this case the two products are the endowed automobile and the replacement automobile.
} 
Proposition 3: Leasing increases the probability that a credit constrained household replaces its automobile.

Figure 2 graphs the combinations of income and willingness to pay for which a household with a given automobile finds it optimal to replace that automobile. ${ }^{11}$ If the household has a willingness to pay equal to $\theta_{S}$, then this household finds the endowed automobile optimal and it does not replace it. If the household has a willingness to pay between $\theta_{S}$ and $\theta_{k p}$ then the household's choice of replacement vehicle is not different enough from their current vehicle to justify the transaction cost of replacement. Finally, if the household's willingness to pay is above $\theta_{k p}$ then if the household is not budget constrained, it will certainly replace. However, if it is budget constrained, whether it replaces depends on how constrained it is from their most preferred vehicle.

This graph shows that there is a region, which is lightly shaded, where budget constrained households would not replace their automobile without the existence of leasing.

Figure 2: Keep/Purchase/Lease Regions

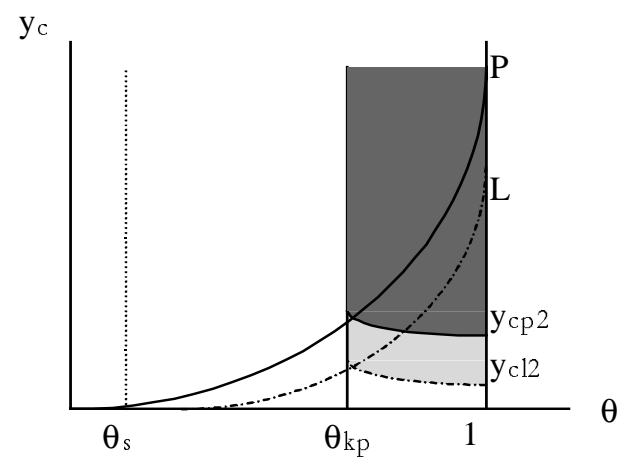

Proposition 4: Any borrowing constrained household who chooses to lease chooses a higher class automobile than the one that she would have purchased. (See Appendix for proof)

\footnotetext{
${ }^{11}$ For a discussion of how this figure was constructed, see Johnson 1999.
} 


\section{Empirical Evidence}

In this section, I present a model of the household's choices in the automobile market. I will use this model to test whether credit constraints affect the decision to lease a new automobile, rather than to purchase a new automobile. In addition, I investigate propositions 3 and 4 of the theoretical model.

The model presented in this section is a discrete choice model of the household's transaction in the automobile market. This paper augments the automobile demand literature by allowing leasing to affect household decision making. I include leasing as an option in a logit model of the household's automobile market transaction. Other studies of this kind include Goldberg (1995); Hensher and Le Plastrier (1985) and Ben-Akiva et.al. (1983).

Other researchers have found little evidence for the hypothesis that borrowing constraints provide a motivation to lease automobiles (Aizcorbe and Starr-McCluer (1996)). In contrast, I find that while households who lease have many similarities to households that purchase, they are more likely to have been turned down for credit for non-financial reasons, such as credit history. In addition, I find that lessees prefer newer, more expensive automobiles, as evidenced by the characteristics of their current automobile stock.

\section{A. Empirical Model to estimate effect of credit constraints on the probability of leasing}

The household chooses an option in the automobile market $i \in\{N A, A P, A L\}$, where the elements of the choice set are: do not acquire a new automobile, purchase a new automobile, or lease a new automobile. ${ }^{12}$ It chooses the option that gives it the maximum utility, where I assume that utility of each action is separable into an observed and an unobserved component. The household chooses i to maximize the utility in equation 17 , where $c_{h}$ is a vector of the household's observable characteristics, $\Omega_{\mathrm{i}}$ is the vector of utility parameters to be estimated, and $\mathrm{u}_{\mathrm{ih}}$ is unobserved utility, where the joint distribution of $u_{\text {ih }}$ is generalized extreme value. ${ }^{13}$

$$
U_{i h}=V\left(c_{h}, \Omega_{i}\right)+u_{i h}
$$

\footnotetext{
12 In 1995, few used automobile could be leased, therefore I restrict leasing to the new car market.

13 Transaction models assess the household decision to enter the market and then consider the choice of vehicle, conditional on the decision to enter. They are generally discrete choice, random utility models (Goldberg 1995; Hensher and Le Plastrier 1985; BenAkiva et.al. 1983).
} 
I assume that leasing and purchasing a new car are close substitutes. With regard to the distribution of the error term, this assumption implies that the error terms for the leasing and purchasing alternatives are correlated. This special case of the GEV distribution is shown in equation 18, where $\lambda$ is a measure of similarity between the lease new and purchase new choices.

$$
F\left(u_{N A}, u_{A P}, u_{A L}\right)=\exp \left\{-\exp \left(-u_{N A}\right)-\left[\exp \left(-u_{A P} / \lambda\right)+\exp \left(-u_{A L} / \lambda\right)\right]^{\lambda}\right\}
$$

The form of utility in equation 17 and the distribution of error terms in equation 18 specify the nested logit shown in figure 3.

Figure 3: Nested Logit Structure

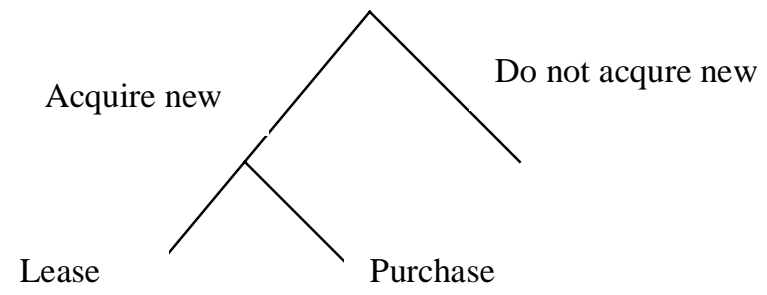

As shown in the figure above, the household's choices can be grouped into the acquisition choice (acquire new or not) and the financing choice (lease or purchase). The choice of acquisition $\mathrm{j}$ and tenure $\mathrm{k}$ gives the household the utility in equation $19 .^{14}$

$$
U_{j k h}=V\left(c_{j k h}, \Omega_{j k h}\right)+u_{j k h}
$$

For simplicity, I assume that the observable portion of utility given in equation 19 is approximately linear in the household's characteristics. Because only differences in utility matter, the utility of not acquiring a new car is normalized to zero. The utilities of all three actions are shown in equation 20, where the first utility subscript refers to the acquisition choice and the second subscript refers to the tenure choice. The utility of acquiring a new car, relative to not acquiring a new car is affected by the variables in vector $x_{h}$. Likewise, the utility of leasing a new car, relative to purchasing a new car is affected by the variables in vector $\mathrm{z}_{\mathrm{h}}$.

$$
\text { (20) } \quad \begin{aligned}
V_{N \bullet h} & =0 \\
V_{A P h} & =\alpha^{\prime} x_{h} \\
V_{A L h} & =\alpha^{\prime} x_{h}+\eta^{\prime} z_{h}
\end{aligned}
$$

14 Following the housing literature, I refer to the choice of leasing or purchasing as the tenure choice. 
Because the utility of each option has an unobserved component, the choice of each option is described probabilistically. Given the distribution of unobserved utility shown in equation 18 and the functional form of observable utilities shown in equation 20, the probabilities for each option are shown in equation 21 where $I_{h}$ is known as the inclusive value variable, and $\mathrm{P}(\mathrm{A})$ is the probability of acquiring a new car. ${ }^{15}$ The parameters of these probabilities are estimated using the maximum likelihood method.

$$
\begin{aligned}
& P(N \bullet)=\frac{1}{1+e^{\pi^{\prime} x_{h}+\lambda I_{h}}} \\
& P(A P)=P(P \mid A) P(A)=\left[\frac{1}{1+e^{\eta^{\prime} z_{h} / \lambda}}\right]\left[\frac{e^{\pi^{\prime} x_{h}+\lambda I_{h}}}{1+e^{\pi^{\prime} x_{h}+\lambda I_{h}}}\right] \\
& P(A L)=P(L \mid A) P(A)=\left[\frac{e^{\eta^{\prime} z_{h} / \lambda}}{1+e^{\eta^{\prime} z_{h} / \lambda}}\right]\left[\frac{e^{\pi^{\prime} x_{h}+\lambda I_{h}}}{1+e^{\pi^{\prime} x_{h}+\lambda I_{h}}}\right] \\
& I_{h}=\ln \left(1+e^{\eta^{\prime} z_{h} / \lambda}\right)
\end{aligned}
$$

\section{B. Data and estimation}

The data used were the 1995 Survey of Consumer Finances (SCF). These data include 4,299 households, where a household is defined as the dominant financially independent person or couple and all persons dependent upon this person or couple. All data missing from the original responses were imputed five times. ${ }^{16}$ The data set therefore contains five separate databases and

\section{1,495 observations.}

Of the 99 million households represented by the SCF, about 9 percent acquired a new automobile in the prior year. Among those who acquired a new automobile roughly $1 / 4$ did so

\footnotetext{
15 The coefficient on the inclusive value variable $(\lambda)$ is a measure of the similarity between the leasing and purchasing alternatives. In order for the model specification to be consistent with utility maximization, this coefficient should lie within the unit interval.

16 This multiple imputation technique increases the efficiency of estimates taken from the dataset because it allows the use of a greater number of observations. It also incorporates information to correct the bias that can also be found in datasets with missing data. This bias results from non-respondents systematically differing from respondents. Multiple imputation allows the standard error of estimates to be corrected for imputation error. The standard errors of all estimates can be corrected for imputation error using the "repeated-imputation inference" (RII) technique (Montalto and Sung 1996). In the RII technique, the best point estimate for the sample is the average of the estimates for each imputation. The best variance estimate is the average of the variances for each imputation, plus a measure of between imputation variance that is adjusted for the number of imputations. Since the measure of between imputation variance must be positive, this will increase the total variance estimate. The higher the number of imputations used, the less weight is placed on the between imputation variance.
} 
under lease, a proportion that is consistent with industry data. The means of the household characteristics used in the estimation are in Table 1; standard deviations are in parentheses. ${ }^{17}$

Most of these variable names are self-explanatory, however, some do require description. The "low time discount" variable is a dummy variable that is set to one if the household reports using a financial planning period of over one year. The "turned down for credit variable" is also a dummy variable. It is set to one if the household reports being turned down for credit in the past five years. Finally, the "low VMT region" variable is a dummy variable that is set equal to one if the consumer lives in a region of the county where the average vehicle miles traveled in that region is less than the national average. ${ }^{18}$

\begin{tabular}{|c|c|c|c|}
\hline Table 1: & $\begin{array}{l}\text { Did Not Acquire } \\
\text { New Car in } 1995\end{array}$ & $\begin{array}{l}\text { Purchased a New } \\
\text { Car in } 1995\end{array}$ & $\begin{array}{c}\text { Leased a } \\
\text { New Car in } 1995\end{array}$ \\
\hline Age of Household Head & $\begin{array}{c}48.9 \\
(0.008)\end{array}$ & $\begin{array}{c}44.2 \\
(0.099)\end{array}$ & $\begin{array}{c}42.0 \\
(0.082)\end{array}$ \\
\hline Years of Education & $\begin{array}{c}12.8 \\
(0.009)\end{array}$ & $\begin{array}{c}14.0 \\
(0.027)\end{array}$ & $\begin{array}{c}14.4 \\
(0.034)\end{array}$ \\
\hline Family Size & $\begin{array}{c}2.54 \\
(0.001)\end{array}$ & $\begin{array}{c}2.87 \\
(0.012)\end{array}$ & $\begin{array}{c}3.30 \\
(0.012)\end{array}$ \\
\hline Female Household Head & $\begin{array}{c}0.30 \\
(0.001)\end{array}$ & $\begin{array}{c}0.11 \\
(0.002)\end{array}$ & $\begin{array}{c}0.14 \\
(0.005)\end{array}$ \\
\hline Non-white or Hispanic Household Head & $\begin{array}{c}0.23 \\
(0.000)\end{array}$ & $\begin{array}{c}0.16 \\
(0.004)\end{array}$ & $\begin{array}{c}0.21 \\
(0.005)\end{array}$ \\
\hline Income & $\begin{array}{c}40,312 \\
(257)\end{array}$ & $\begin{array}{c}81,579 \\
(875)\end{array}$ & $\begin{array}{l}90,964 \\
(3,372)\end{array}$ \\
\hline Average Age of other vehicles in stock & $\begin{array}{c}9.29 \\
(0.015)\end{array}$ & $\begin{array}{c}8.13 \\
(0.050)\end{array}$ & $\begin{array}{c}5.78 \\
(0.062)\end{array}$ \\
\hline Average Value of other vehicles in stock & $\begin{array}{l}6,124 \\
(24.4)\end{array}$ & $\begin{array}{l}7,399 \\
(86.4)\end{array}$ & $\begin{array}{c}10,747 \\
(147)\end{array}$ \\
\hline Low Time Discount & $\begin{array}{c}0.60 \\
(0.001)\end{array}$ & $\begin{array}{c}0.72 \\
(0.004)\end{array}$ & $\begin{array}{c}0.78 \\
(0.005)\end{array}$ \\
\hline Low VMT Region & $\begin{array}{c}0.50 \\
(0.001)\end{array}$ & $\begin{array}{c}0.49 \\
(0.004)\end{array}$ & $\begin{array}{c}0.70 \\
(0.007)\end{array}$ \\
\hline
\end{tabular}




$\begin{array}{lccc}\text { Percent Homeowners } & 0.55 & 0.70 & 0.78 \\ & (0.001) & (0.003) & (0.002) \\ \text { Percent Home Equity } & 0.70 & 0.63 & 0.61 \\ & (0.001) & (0.004) & (0.013) \\ \text { Credit Card Dummy } & 0.65 & 0.85 & 0.93 \\ & (0.001) & (0.004) & (0.001) \\ \text { Turned Down for Credit } & 0.12 & 0.09 & 0.16 \\ & (0.000) & (0.004) & (0.001)\end{array}$

I estimated the nested logit model sequentially with the complete data set. I estimated the model five times, once for each imputation and corrected the standard errors using Repeated Imputation Inference (RII). ${ }^{19}$ Table 2 shows the estimated parameter coefficients and their standard errors.

\begin{tabular}{lcc} 
Table 2: & $\begin{array}{c}\text { Lease/Purchase } \\
\text { Submodel }\end{array}$ & $\begin{array}{c}\text { Acquire new/Do not acquire } \\
\text { new Submodel }\end{array}$ \\
\hline Constant & $-2.624 *$ & $-3.93 *$ \\
& $(0.633)$ & $(0.405)$ \\
Age of Household Head & -- & $-0.010 * *$ \\
& & $0.004)$ \\
Years of Education & -- & $0.079 *$ \\
& & $(0.022)$ \\
Family Size & -- & $0.070 * * *$ \\
& & $(0.039)$ \\
Female Household Head & -- & $-0.798 *$ \\
& & $(0.176)$ \\
Non-white or Hispanic Household Head & $0.584 * * *$ & -0.134 \\
& $(0.309)$ & $(0.200)$ \\
Income & $-9.96 \times 10-8$ & $3.01 \times 10-9$ \\
& $(8.93 \times 10-8)$ & $(1.83 \times 10-8)$ \\
Average Age of Vehicle Stock & $-0.088 *$ & $-0.071 *$ \\
Average Value of other vehicles in stock & $(0.027)$ & $(0.018)$ \\
& & \\
19 See Montalto and Sung (1996). & $1.96 \times 10-5 * *$ & $2.95 \times 10-5 *$ \\
& $(9.66 \times 10-6)$ & $(6.44 \times 10-6)$ \\
& & \\
& &
\end{tabular}


Low Time Discount

Low VMT Region

Percent Homeowners

Percent Home Equity

Credit Card Dummy

Turned Down for Credit

Inclusive Value

* Significant at the 1 percent level

**Significant at the 5 percent level

***Significant at the 10 percent level
0.180

$0.585 *$

$-0.086$

(0.212)

$0.860 * *$

$0.517 * *$

(0.257)

$-0.756 * *$

0.319

(0.342)

$1.02 * * *$

$0.879 *$

$1.25 *$

$-0.189$

Table 3 shows the variables marginal effects on the probabilities estimated. In support of the assumption that credit constraints matter, whether a household had been turned down for credit in the past five years had a large, significant effect on the conditional probability of leasing. As summarized in the first column of Table 3, an average household who acquired a new automobile and had been turned down for credit had a 19 percent conditional probability of leasing whereas the odds that an average household turned down for credit leased an automobile was $35-1 / 2$ percent - a 16-1/2 percentage point difference. Most households who had been turned down cited reasons related to past credit history, rather than low income, high debt or personal reasons.

In addition, households belonging to racial or ethnic groups who are more likely to be credit constrained had a higher conditional probability of leasing. Non-white or Hispanic households had a conditional probability of leasing that was nearly 8 percentage points higher than that of white households.

Proposition 3 of the theoretical model implies that leasing has increased the probability of replacement for credit constrained consumers. Households that purchased a new automobile and those that leased a new automobile both had newer automobiles in their current stock. Those that 
leased, however, clearly preferred newer automobiles than those that purchased. A one year decrease in the average age of the vehicle stock increased the conditional probability that a household leased by about 1-1/4 percentage points. This result implies that households who lease replace their automobile more often than those that purchase.

In addition, proposition 4 of the theoretical model suggests that lessors should lease more expensive automobiles than the ones that they would have purchased. Since this empirical model does not include the household's choice of automobile make or model, it cannot predict which automobile the household would have purchased in the absence of leasing. However, households who seemed to prefer more expensive automobiles, as measured by the average value of automobile they already own or lease, were more likely to lease the next vehicle. For every $\$ 10,000$ increase in this average value, the probability that the household leased the next automobile rose by about 2-1/2 percentage points. Some lessees may prefer higher value automobiles than automobile buyers and may have leased an automobile rather than purchase a less expensive automobile for which they could secure an auto loan. This is consistent with Mannering, Starkey and Winston (1999) who postulate that leasing results from households who desire to "upgrade" their vehicles. If automobile price and quality are positively correlated, then this result is also consistent with Hendel and Lizzeri (1998) who demonstrate that consumers who place a high value on automobile quality choose a leasing contract.

Guha and Waldman (1997) find that lessees are consumers with a high cost of maintaining their automobiles. They predict that high income consumers are more likely to lease because a higher cost of time leads to higher maintenance costs. In contrast to this view, many measures of the household's financial position, including income, total assets, total debt and debt service burden, in general, did not affect significantly the probability of leasing.

Some have speculated that purchasers have greater home equity, which could be used to finance an automobile purchase. Households who purchased were less likely to own their own home than those that leased, however, they did have more home equity. Some have also speculated that lessees may be more impatient households. According to this view, impatient households lease automobiles because they prefer lower monthly payments. I tested this hypothesis using a time discount rate dummy to measure the household's patience. This variable 
was insignificant in preliminary estimations and, in fact, more lessees had a low discount rate, contrary to the hypothesis that lessees are impatient.

Households who leased also tended to live in regions where the average miles traveled by automobile is lower than the national average. A household in a low VMT region had a probability of leasing that was nearly 8 percentage points above that of a household in a high VMT region. This result suggests that the mileage restrictions may be binding in most cases, and are necessary for collateral protection.

Table 3:

$\partial \operatorname{Pr} o b(L \mid A), \partial \operatorname{Pr} o b(L) / \partial x \partial \operatorname{Pr} o b(P) / \partial x \quad \partial \operatorname{Pr} o b(N A) / \partial x$

\begin{tabular}{lcccc}
\hline Age of Household Head & -- & -0.000 & -0.001 & 0.001 \\
Years of Education & -- & 0.002 & 0.005 & -0.007 \\
Family Size & -- & 0.001 & 0.005 & -0.006 \\
Female Household Head & -- & -0.016 & -0.053 & 0.069 \\
Non-white or Hispanic Household Head & 0.077 & 0.009 & -0.015 & 0.007 \\
Income & $-0.013 \times 10-6$ & $-0.019 \times 10-7$ & $0.013 \times 10-7$ & $0.060 \times 10-8$ \\
Average Age of Vehicle Stock & -0.012 & -0.003 & -0.004 & 0.007 \\
Average Value of other vehicles in stock & $0.026 \times 10-4$ & $0.097 \times 10-5$ & $0.018 \times 10-4$ & $-0.027 \times 10-4$ \\
Low Time Discount & -- & 0.004 & 0.012 & -0.016 \\
Low VMT Region & 0.078 & 0.010 & -0.012 & 0.002 \\
Percent Homeowners & 0.114 & 0.030 & 0.025 & -0.052 \\
Percent Home Equity & -0.100 & -0.008 & 0.030 & -0.021 \\
Credit Card Dummy & 0.135 & 0.037 & 0.048 & -0.085 \\
Turned Down for Credit & 0.166 & 0.021 & -0.026 & 0.006
\end{tabular}

\section{Conclusion}

Leasing is an alternative financial contract in which a household has the option to finance the user cost of an automobile rather than the entire purchase price. In return, the household agrees to terms that protect the automobile as collateral. Leasing loosens the credit constraint on individuals who are willing to enter these contracts. Among those households for whom the credit constraint would bind if they purchased an automobile, leasing may affect their decision to acquire another automobile. Since they are able to acquire an automobile that they otherwise might not have been able to acquire, they may be more likely to do so.

The theoretical model presented in section III represents the household's decision to replace their automobile. It incorporates credit constraints in order to distinguish between the leasing and purchasing options. This model of the household demonstrated how leasing can 
increase the probability that a household replaces its automobile and how those households who lease choose higher quality automobiles.

The empirical model provided some evidence in support of these observations. In particular, it provides support for the notion that households who lease face credit constraints, at least in their recent past. It also showed that while households who lease new automobiles are quite similar to those that purchase, they exhibit differences consistent with the theory. Besides being more credit constrained, they prefer newer, more expensive automobiles, have less home equity with which to purchase automobiles and live in regions where the mileage restraints on leasing are less likely to bind. 


\section{REFERENCES}

Aizcorbe, A., and M. Starr-McCluer, "Vehicle Ownership, Vehicle Acquisitions and the Growth of Auto Leasing: Evidence from the Consumer Surveys," Board of Governors of the Federal Reserve System Working Paper (1996).

Bar-Ilan and Blinder, "Consumer Durables: Evidence on the Optimality of Usually Doing Nothing," Journal of Money, Credit and Banking, v. 24, n.2, May 1992.

CNW Marketing Research, Lease Penetration: Passenger Cars.

Goldberg, P., "Product Differentiation and Oligopoly in International Markets: The Case of The U.S. Automobile Industry,” Econometrica, v. 63, n. 4, July 1995.

Hensher, D., "Sequential and Full Information Maximum Likelihood Estimation of a Nested Logit Model," The Review of Economics and Statistics, v. 68, n. 4 (November 1986).

Hensher, D., and V. LePlastrier, "Towards a Dynamic Discrete-Choice Model of Household Automobile Fleet Size and Composition," Transportation Research, v. 19B, n. 6, 1985.

Hocherman, I., J Prashker and M. Ben-Akiva, "Estimation and Use of Dynamic Transaction Models of Automobile Ownership," Transportation Research Record, n. 944, 1983.

Horowitz, J.L., "Specification Tests for Nested Logit Models," Environment and Planning A, v. 19 (1987).

Johnson, K., The Effect of Consumer Automobile Leasing on Replacement Decisions, Ph.D. Thesis, University of Maryland (1999).

Kennickell, A.B., D. Mc Manus and R. Woodburn, "Weighting Design for the 1992 Survey of Consumer Finances," Board of Governors of the Federal Reserve System Working Paper (1996).

Kennickell, A.B., and R.L. Woodburn, "Consistent Weight Design for the 1989, 1992 and 1995 SCF's and the Distribution of Wealth," Board of Governors of the Federal Reserve System Working Paper (1997).

Maddala, G., Limited Dependent Variables and Qualitative Variables in Econometrics, Cambridge University Press (1983).

Mannering, F., W. Starkey and C. Winston, "An Exploratory Analysis of Automobile Leasing in the United States,” Working Paper (1999).

Mannering, F. and K. Train, "Recent Directions in Automobile Demand Modeling," Transportation Research, v. 19B, n.4 1985. 
McFadden, D., "Modeling the Choice of Residential Location," in Spacial Interaction Theory and Planning Models, Karqvist et. al., eds.

Miller, Stephen. "Economics of Automobile Leasing: The Call Option Value" Journal of Consumer Affairs 29 (Summer 1995): 199-218.

Montalto C., and J. Sung, "Multiple Imputation in the 1992 Survey of Consumer Finances," Financial Counseling and Planning, 7, 133-146.

Nunnally, B. and D. Plath, "Leasing Versus Borrowing: Evaluating Alternative Forms of Consumer Credit," The Journal of Consumer Affairs, v. 23, n. 2 (Winter 1989).

Patrick, T., "A Proposed Procedure for Facilitating the Analysis of Lease-Purchase Decisions by Consumers," The Journal of Consumer Affairs, v. 18, n. 2 (Winter 1984).

Scerbinski, V., "Cash Purchase, Finance or Lease of an Automobile: Financial Models Designed to Provide the Answer," Tax Notes (April 25, 1988).

Survey of Consumer Finances, Board of Governors of the Federal Reserve System, 1995.

Tirole, J., The Theory of Industrial Organization, MIT Press, Cambridge MA (1988).

Train, K., Qualitative Choice Analysis: Theory, Econometrics and an Application to Automobile Demand, The MIT Press, Cambridge (1986).

U.S. Data on Demand, Inc.and State Policy Research. Inc., States in Profile: The State Policy Reference Book (1994). 


\section{APPENDIX}

\section{Proof of Proposition 1}

Suppose the borrowing constrained household's current plus borrowed future income is less than the transaction cost and subsistence level of consumption, i.e. $y_{c}\left(1+\frac{d}{R}\right)<t+w$. Adding $\mathrm{S}$ to both sides and rearranging gives us $h\left[y_{c}\left(1+\frac{d}{R}\right)-w+p(S)-t\right]-S<0$. The decision rule for replacement in this case is:

do not replace if $\theta>\beta\left(R-\gamma^{\varepsilon}\right)\left[y_{c}\left(1+\frac{d}{R}\right)-w\right]+\beta \gamma^{\varepsilon} t / h\left[y_{c}\left(1+\frac{d}{R}\right)-w+p(S)-t\right]-S$. The left hand side of this condition is positive by assumption. The numerator of the right hand side is positive since both $w<y_{c} \Rightarrow y_{c}\left(1+\frac{d}{R}\right)-w>0$ and $\gamma<1$. The denominator of the right hand side is negative since $h\left[y_{c}\left(1+\frac{d}{R}\right)-w+p(S)-t\right]-S<0$. Therefore, this condition holds and it is optimal for the consumer to keep her current automobile.

\section{Proof of Proposition 2}

Assume that $\mathrm{t}=0$ and the non-borrowing constrained household finds it optimal to keep its automobile. This implies that $V_{R}-V_{K}=\frac{\theta}{b}\left[g\left(\frac{\theta}{b}\right)-S\right]+p(S)-p\left(g\left(\frac{\theta}{b}\right)\right)<0$ where $b=\beta\left(R-\gamma^{\varepsilon}\right)$. Note that $\frac{\theta}{b}=p^{\prime}\left(g\left(\frac{\theta}{b}\right)\right)$, implying $p^{\prime}\left(g\left(\frac{\theta}{b}\right)\right)\left[g\left(\frac{\theta}{b}\right)-S\right]<p\left(g\left(\frac{\theta}{b}\right)\right)-p(S)$.

But by the strict convexity of $\mathrm{p}(.) \quad p^{\prime}\left(g\left(\frac{\theta}{b}\right)\right)\left[g\left(\frac{\theta}{b}\right)-S\right]>p\left(g\left(\frac{\theta}{b}\right)\right)-p(S)$. Contradiction.

\section{Proof of Proposition 4}

There are two types borrowing constrained households, one type is borrowing constrained whether it leases or it purchases and the other type is borrowing constrained only when it purchases. For either type, the choice of automobile services when the household purchases is equal to $s_{P}^{B}=h\left[\left(1+\frac{d}{R}\right) y_{c}+p(S)-t-w\right]$.

The first type of household chooses to lease automobile services equal to:

$s_{L}^{B}=h\left[\frac{R}{R-\gamma^{\varepsilon}}\left(\left(1+\frac{d}{R}\right) y_{c}+p(s)-t-w\right)\right]$. Since $\frac{R}{R-\gamma^{\varepsilon}}>1^{2}$ and $h^{\prime}()>0, s_{L}^{B}>s_{P}^{B}$

The second type of household chooses to lease automobile services equal to: 
$s_{L}^{N}=g\left(\frac{\theta}{\beta\left(R-\gamma^{\varepsilon}\right)}\right) \cdot$ This household's borrowing constraint if they were to purchase this amount of automobile services is $p\left(g\left(\frac{\theta}{b}\right)\right)+t+w-y_{c}-p(S)>\frac{d}{R} y_{c}$. Rearranging gives us:

$s_{L}^{N}=g\left(\frac{\theta}{\beta\left(R-\gamma^{\varepsilon}\right)}\right)>h\left[\left(1+\frac{d}{R}\right) y_{c}+p(S)-t-w\right]=s_{P}^{B}$ 